РОЗРОБЛЕННЯ ТА МОДЕРНІЗАЦІЯ ОВТ

UDC 629.113

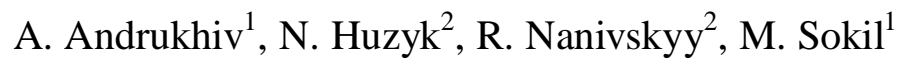 \\ ${ }^{I}$ National University «Lviv Polytechnic», Lviv \\ ${ }^{2}$ National Academy of Land Forces named after Hetman Petro Sakhajdachnyj, Lviv
}

\title{
INFLUENCE OF FORCE CHARACTERISTICS OF COMBAT-WHEELED VEHICLES' SYSTEM OF SPRINKLING ON SHOOTING EFFICIENCY ON MOVE
}

\begin{abstract}
The experience of peacekeeping and other military operations shows the growing role of the combat-wheeled vehicles. However, the combat-wheeled vehicles suspension for the base for which a chassis of a serial wheeled vehicle was selected with the armored corps in it does not fully protect the personnel from dynamic overloads while driving with significant irregularities or cross-country terrain. The armored corps causes a significant increase in the weight of the sprinkled part and so a static deformation of elastic shock absorbers, and also a number of operational features. In order to overcome the above-mentioned disadvantages we modernize the system of sprinkling using the shock absorbers with nonlinear (progressive or regressive) characteristics for such combatwheeled vehicles. However, the influence of the nonlinear force characteristics of the combat-wheeled vehicles' system of sprinkling on the shooting efficiency on the move from stationary mounted small arms are not investigated due to a number of reasons. They relate to the construction and investigation of the solutions to the nonlinear differential equations, which are the mathematical models of the combat-wheeled vehicles' motion.

In this paper, we investigate the influence of the power characteristics of the system of sprinkling of combatwheeled vehicles on the transverse oscillations of the sprinkled part, and on the shooting efficiency on move from the stationary mounted small arms. The basis for the determining of these characteristics serve the differential equation of the sprinkled part's perturbed motion. We use the Van der Pol method, adapted to strongly nonlinear differential equations for its integration.

It is shown that the magnitude of the dispersion caused by the indicated oscillations of the sprinkled part increases, and in the case of the progressive power characteristic of elastic shock absorbers during the motion along the path with single irregularities the value of the scattering region is greater than that of the regressive one.
\end{abstract}

Keywords: system of sprinkling, combat-wheeled vehicle, amplitude, frequency of oscillations.

\section{Statement of the problem}

The experience of peacekeeping and other military operations shows the growing role of the combatwheeled vehicles. They are characterized by a high degree of protection of the personnel from the defeat, maneuverability, and others. However, the combatwheeled vehicles suspension does not fully protect the personnel from dynamic overloads while driving with significant irregularities or cross-country terrain, and greatly affects on shooting efficiency on move from stationary mounted small arms. This primarily concerns to the combat-wheeled vehicles for the base for which a chassis of a serial wheeled vehicle was selected with the armored corps in it. The latter causes not only a significant increase in the weight of the sprinkled part and so a static deformation of elastic shock absorbers, but also a number of operational features. This is primarily the overload of the driver and the crew in difficult traffic conditions, loss of stability, lowering of the shooting efficiency on the move, and hence, the failure of the fulfill task.
In order to overcome the above-mentioned disadvantages we modernize the system of sprinkling using the shock absorbers with nonlinear (progressive or regressive) characteristics for such combat-wheeled vehicles. These shock absorbers significantly more effectively protect the combat-wheeled vehicles from such an undesirable phenomenon as breakdown, reduce the dynamic loads that act on the driver and the crew while moving cross-country terrain to almost $30 \%$, which is especially important during the transportation of the injured people.

However, the influence of the nonlinear force characteristics of the combat-wheeled vehicles' system of sprinkling on the shooting efficiency on the move from stationary mounted small arms are not investigated due to a number of reasons. They relate to the construction and investigation of the solutions to the nonlinear differential equations, which are the mathematical models of the combat-wheeled vehicles' motion. 
We assume that, it is necessary to investigate the influence of the main force characteristics of the combat-wheeled vehicles' system of sprinkling and the sprinkled part's kinematic parameters on the shooting efficiency on the move from stationary mounted small arms. Namely combat-wheeled vehicles with spring shock absorbers' nonlinear-elastic characteristic move at a velocity $V$ along a straight line section of the path with irregularities.

Our assumptions about the physical model are the following:

- sprinkled and unsprinkled parts are completely solid bodies that interact with each other by the system of sprinkling;

- the mass of the unsprinkled part is much smaller than the mass of the sprinkled part and we neglected it in the work;

- the force characteristics of shock absorbers are described by their nonlinear deformation functions $\Delta$, and deformation rate of damper devices $\dot{\Delta}$. Elastic force of shock-absorbers is equal to $F_{e l}=c \Delta^{v+1}$, strength of resistance of damper devices is equal to $R_{\text {res }}=\alpha \dot{\Delta}^{2 s+1}$ where $c, v, \alpha, s$ are the known constants;

- the deformation of the pneumatic wheels is much less than the deformation of elastic shock absor-bers while the combat-wheeled vehicles move along the path with the irregularities. This means that the pneumatic shaft are considered as the absolutely solid bodies, and the sprinkled part, due to perturbations from single irregularities, carries the transverse angular oscillations around the longitudinal horizontal axis. This axis passes through the sprinkled part's center of the weight.

Our aim is to determine the sprinkled part's basic characteristics of transverse angular oscillations, which are caused by the combat wheeled vehicles' motion along the path with the system of single irregularities, and, on the other hand, the influence of the indicated oscillations on the dispersion of projectiles departed from stationary mounted on it small arms.

\section{Analysis of basic research and publications}

Note that in the papers [1-8], which relate to the dynamics of the combat-wheeled vehicles system of sprinkling with the nonlinear power characteristic, the focus is on ergonomic indicators, motion stability, resonance, and others. However, the questions related to the influence of the sprinkled part dynamics on the shooting efficiency on the move from the stationary mounted small arms did not considered in these works.

\section{Purpose of the article}

The aim of this paper is to investigate the influence of the combat-wheeled vehicles' longitudinal-angular oscillations on the shooting efficiency on the move from the stationary mounted small arms, which implies its relevance.

\section{Method of solving}

The basis for the determining of the transverse angular oscillations' main characteristics will serve the differential equation of the sprinkled part's perturbed motion, which, taking into account the above, can be represented as

$$
I_{O} \frac{d^{2} \vartheta(t)}{d t^{2}}=-4 c l\left(\vartheta l-\frac{1}{2} z(t)\right)^{v+1}-\alpha l\left(l \frac{d \vartheta(t)}{d t}-\frac{d z}{d t}\right)^{2 s+1} .
$$

In the formula (1) we denote by $I_{0}$ the sprinkled part's moment of inertia relative to the horizontal longitudinal axis, passing through the sprinkled part's center of the weight. Moreover, we denote by $\vartheta$ the sprinkled part's angle of rotation around the indicated axis, by $\Delta_{s t}$ static deformation of elastic shock absorbers, by $l$ the half of the distance between points of fixation of elastic shock absorbers (dampers) and the sprinkled part and by $z(t)$ the function that describes the irregularities. We assume that this function for the case of single irregular-rities has the form

$$
z(t)=\left\{\begin{array}{l}
h_{j} \sin ^{2 s_{j}} \frac{2 \pi V t}{d_{j}}, \text { if } x_{j} \leq x \leq x_{j}+d_{j} \\
0, \text { if } x_{j}+d_{j} \leq t \leq x_{j+1}, j=1,2,3, \ldots,
\end{array}\right.
$$

where $h_{j}$ denotes the height of the $j$ irregularity, $d_{j}$ is her lengths and $s_{j}$ is the constant which describes her form. We denote by $x_{j}, x_{j+1}$ the coordinates of the beginning of $j$ and $j+1$ irregularities respectively, by $V$ the combatwheeled vehicles' speed of movement.

We will assume below that:

- the system of sprinkling's force characteristics of the right and left sides are identical, and the sprinkled part's oscillations are due to only the right side wheel rudder to the irregularity;

- the height of the irregularities is small in comparison with the static deformation of elastic shock absorbers $\left(\Delta_{t}\right)$.

Thus, to solve to the problem above we have to construct a solution of the nonlinear differential equation (1), with the function $z(t)$ determined by the relation (2).

Neglecting the highest order of smallness, we can rewrite the equation (1) in the form

$$
\frac{d^{2} \vartheta(t)}{d t^{2}}+\frac{4 c l}{I_{O}}(\vartheta l)^{v+1}=\frac{1}{I_{O}}\left[2 c l(v+1)(\vartheta l)^{v} z(t)-4 \alpha l\left(l \frac{d \vartheta(t)}{d t}-\frac{1}{2} \frac{d z}{d t}\right)^{2 s+1}\right] .
$$


The maximum value of the right-hand side of the differential equation (3) is small in comparison with the maximum value of the relation $\frac{4 c l}{I_{O}}(\vartheta l)^{v+1}$, and therefore, we can use, for example, the Van der Pol method, adapted to strongly nonlinear differential equations for its integration. Accordingly to its main idea [9], we describe sprinkled part's transverse angular oscillations of the combat-wheeled vehicles by dependence

$$
\begin{gathered}
\vartheta(t)=a_{\vartheta}(t) c a(v+1,1, \psi), \\
\psi=\omega\left(a_{\vartheta}\right) t+\theta(t)
\end{gathered}
$$

where $a(t)$ is a amplitude of the transverse angular oscillations. As a function of time it is determined by the right side of the differential equation (3), the eigen frequency $\omega$ as the function of the amplitude takes value where

$$
\begin{gathered}
\omega(a)=\sqrt{2 c l^{v+2}(v+2) / I_{0}} a^{\frac{v}{2}}, \\
\psi=\omega\left(a_{\vartheta}\right) t+\theta(t)
\end{gathered}
$$

denotes their phase of oscillations.

Without the method of determining of the main parameters of sprinkled part's transverse angular oscillations of the combat-wheeled vehiclei, we give only the resulting dependences for the case of the irregularities of insignificant lengths. For these irregularities, we suppose that the time of the move $\tau$ along them is small in comparison with the sprinkled part's period of the internal oscillations. Thus, the amplitude of the sprinkled part's oscillations changes accordingly to the differential equation (5).

We give the values of the amplitude of transverse angular oscillations in the Table 1. The results in it are based on the numerical simulation of the equation (5).

$$
\frac{d a}{d t}=\frac{1}{\omega(a) I_{0}}\left\{\begin{array}{l}
2 c(v+1) l^{v+1} a^{v} \sin ^{2 s_{j}-1} \frac{2 \pi V}{d_{j}} t-\alpha\left(l \dot{\vartheta}(t)-h_{j} 4 s_{j} \sin ^{2 s_{j}-1} \frac{2 \pi V}{d_{j}} t \cos \frac{2 \pi V}{d_{j}} t\right)^{2 s+1}, \text { if } t_{j} \leq t \leq t_{j}+\frac{d_{j}}{V}, \\
-4 \alpha(l \dot{\vartheta}(t))^{2 s+1}, \text { if } \quad t_{j}+\frac{d_{j}}{V} \leq t \leq t_{j+1}+\frac{d_{j+1}}{V} .
\end{array}\right.
$$

Table 1

The value of the amplitude of the vertical oscillations of the combat-wheeled vehicles' sprinkled part at the moment of the output of the lone irregularity for different values of the speed and parameters of the force characteristic of the shock absorbers

\begin{tabular}{|c|c|c|c|c|c|c|c|c|c|c|c|}
\hline$d_{1}, m$ & $\Delta_{s t}, \mathrm{~m}$ & $v$ & $\mathrm{~V}, m / s$ & $\mathrm{~h}, m$ & $\mathrm{a}, \mathrm{rad}$ & $d_{1}, m$ & $\Delta_{s t}, \mathrm{~m}$ & $v$ & $\mathrm{~V}, m / s$ & $\mathrm{~h}, m$ & $\mathrm{a}, \mathrm{rad}$ \\
\hline 0.3 & 0.25 & 0 & 5 & 0.2 & 0.2784 & 0.2 & 0.15 & $-2 / 5$ & 5 & 0.2 & 0.1723 \\
\hline 0.3 & 0.2 & 0 & 5 & 0.2 & 0.2618 & 0.2 & 0.15 & $-2 / 5$ & 10 & 0.2 & 0.0634 \\
\hline 0.3 & 0.15 & 0 & 5 & 0.2 & 0.2483 & 0.2 & 0.15 & $-2 / 5$ & 15 & 0.2 & 0.0391 \\
\hline 0.4 & 0.15 & 0 & 5 & 0.2 & 0.3279 & 0.2 & 0.25 & $-2 / 7$ & 5 & 0.2 & 0.1684 \\
\hline 0.4 & 0.15 & 0 & 10 & 0.2 & 0.1583 & 0.2 & 0.25 & $-2 / 7$ & 10 & 0.2 & 0.0823 \\
\hline 0.4 & 0.15 & 0 & 15 & 0.2 & 0.1132 & 0.2 & 0.25 & $-2 / 7$ & 15 & 0.2 & 0.0531 \\
\hline 0.2 & 0.25 & $-2 / 5$ & 5 & 0.2 & 0.1578 & 0.3 & 0.25 & $-2 / 7$ & 5 & 0.2 & 0.2584 \\
\hline 0.2 & 0.25 & $-2 / 5$ & 10 & 0.2 & 0.0743 & 0.3 & 0.25 & $-2 / 7$ & 10 & 0.2 & 0.1269 \\
\hline 0.2 & 0.25 & $-2 / 5$ & 15 & 0.2 & 0.0453 & 0.3 & 0.25 & $-2 / 7$ & 15 & 0.2 & 0.0814 \\
\hline 0.4 & 0.25 & $4 / 7$ & 5 & 0.2 & 0.4231 & 0.4 & 0.25 & $-4 / 7$ & 5 & 0.2 & 0.3365 \\
\hline 0.4 & 0.25 & $4 / 7$ & 10 & 0.2 & 0.2302 & 0.4 & 0.25 & $-4 / 7$ & 10 & 0.2 & 0.1483 \\
\hline 04 & 0.25 & 0 & 10 & 0.2 & 0.1893 & 04 & 0.25 & 0 & 15 & 0.2 & 0.1003 \\
\hline 0.4 & 0.25 & $4 / 7$ & 15 & 0.2 & 0.1701 & 0.4 & 0.25 & $-4 / 7$ & 15 & 0.2 & 0.0884 \\
\hline 0.4 & 0.15 & $-2 / 7$ & 5 & 0.2 & 0.3182 & 0.2 & 0.2 & $2 / 5$ & 5 & 0.2 & 0.2014 \\
\hline 0.4 & 0.15 & $-2 / 7$ & 10 & 0.2 & 0.1465 & 0.2 & 0.2 & $2 / 5$ & 10 & 0.2 & 0.1142 \\
\hline 0.4 & 0.15 & $-2 / 7$ & 15 & 0.2 & 0.0948 & 0.2 & 0.2 & $2 / 5$ & 15 & 0.2 & 0.0843 \\
\hline 0.3 & 0.25 & 0 & 10 & 0.2 & 0.1483 & 0.3 & 0.25 & $2 / 7$ & 10 & 0.2 & 0.1673 \\
\hline 0.3 & 0.25 & 0 & 10 & 0.15 & 0.1271 & 0.3 & 0.25 & $2 / 7$ & 10 & 0.15 & 0.1394 \\
\hline 0.3 & 0.25 & 0 & 10 & 0.1 & 0.0853 & 0.3 & 0.25 & $2 / 7$ & 10 & 0.1 & 0.1051 \\
\hline 0.3 & 0.25 & $-2 / 7$ & 10 & 0.15 & 0.0972 & 0.3 & 0.25 & $-2 / 7$ & 10 & 0.1 & 0.0685 \\
\hline
\end{tabular}

We conclude from the results of the table 1 that during the combat-wheeled vehicles' motion along the path with irregularities, the sprinkled part's amplitude of the transverse angular oscillations is lower in the cases: 
- the smaller lengths of the irregularities (for the same speeds of motion);

- the higher speeds (for identical profiles of the irregularities);

- the sprinkled part's regressive force characteristics (for identical static deformations of elastic shock absorbers);

- the sprinkled part with a lower value of static deformation of elastic shock absorbers.

The obtained dependencies are simultaneously the basis of the estimation of the influence of the sprinkled part's oscillations of the combat-wheeled vehicles on the shooting efficiency on the move from stationary mounted small arms. Let the coordinates of the point D, which coincides with the small arms' center of the muzzle cut in the reference frame $C \xi \eta \zeta$ constantly connected to the sprinkled part's center of masses, are $D\left(\xi_{D}, \eta_{D}, \zeta_{D}\right)$. We assume that the axis $C \eta$ coincides with the longitudinal axis. Then the coordinates of a given point at an arbitrary moment of the time, due to the sprinkled part's rotation at an angle $\vartheta$, will be:

$\left(\sqrt{\xi_{D}^{2}+\zeta_{D}^{2}} \cos (\beta+\vartheta), \eta_{D}, \sqrt{\xi_{D}^{2}+\zeta_{D}^{2}} \sin (\beta+\vartheta)\right)$

with $\beta=\arcsin \frac{\zeta_{D}}{\sqrt{\xi_{D}^{2}+\zeta_{D}^{2}}}$.

These arguments allow us to find the horizontal $H_{\xi}$ and vertical $H_{\zeta}$ components of the movement of a point that coincides with the center of the muzzle cut

$$
\begin{aligned}
& H_{\xi}=\sqrt{\xi_{D}^{2}+\zeta_{D}^{2}} \cos (\beta+\vartheta)-\xi_{D}, \\
& H_{\zeta}=\sqrt{\xi_{D}^{2}+\zeta_{D}^{2}} \sin (\beta+\vartheta)-\zeta_{D} .
\end{aligned}
$$

If the sprinkled part's angle of rotation is limited to its maximum value, we obtain the maximum horizontal $\bar{H}_{\xi}$ and vertical $\bar{H}_{\zeta}$ displacement of the point $D$ :

$$
\begin{aligned}
& \bar{H}_{\xi}=\sqrt{\xi_{D}^{2}+\zeta_{D}^{2}} \cos (\beta+a)-\xi_{D}, \\
& \bar{H}_{\zeta}=\sqrt{\xi_{D}^{2}+\zeta_{D}^{2}} \sin (\beta+a)-\zeta_{D} .
\end{aligned}
$$

These parameters are basic for the estimation of the influence of the transverse angular oscillations on the shooting efficiency on the move from stationary mounted small arms. Taking into account that the law of dispersion of the projectiles is normal [10], we establish the relationship between the magnitude of the deviation of the projectile from the center of dispersion and the probability of this deviation. Scale of dispersion of the projectiles allows us to specify the percentage of hit of the projectile at a certain interval. So the percentage of hit in the interval $(-1 \sigma,+1 \sigma)$, the center of which is the point $\mathrm{C}$ (the center of dispersion of projectiles), where $\sigma$ denotes the median deviation in range, is $50 \%$, and in $(+1 \sigma,+2 \sigma)-16 \%$, in $(+2 \sigma,+3 \sigma)-7 \%$ and in $(+3 \sigma,+4 \sigma)-2 \%$ of the projectiles. If a projectile is released from a point with coordinates $\left(0 ; \zeta_{D}\right)$ with an initial velocity $v_{0}$ and at an angle $\alpha$ to the horizon, than the point of its fall $\mathrm{C}$ is determined by the coordinates

$$
x_{C}=\frac{v_{0} \sin 2 \alpha}{2 g}+\frac{v_{0} \cos \alpha}{g} \sqrt{v_{0}^{2} \sin ^{2} \alpha+2 g \zeta_{D}}, y_{C}=0 .
$$

In the given dependence, we do not take into account the forces of the resistance to the motion of the projectiles. If the abscissa of the landing of the projectile (the center of the fall) $x_{C}$ is a random variable, then, accordingly to the normal dispersion law [11], the probability that the absolute value of the deviation $\left|x_{C}-m\right|$ will be less than the positive number $\mathrm{k}$ is equal to

$$
P\left(\left|x_{C}-m\right|<k\right)=2 \Phi\left(\frac{k}{\sigma}\right),
$$

where $\Phi(x)=\frac{1}{\sqrt{2 \pi}} \int_{0}^{x} e^{-\frac{t^{2}}{2}} d t$ is a Laplace function.

In the consequence of the sprinkled part's oscillations of the combat-wheeled vehicles the departure height $\zeta_{D}$ of the projectile will change to a positive number $\bar{H}_{\zeta}$, and therefore the projectile will land at the point with the coordinates

$$
A\left(\frac{v_{0} \sin 2 \alpha}{2 g}+\frac{v_{0} \cos \alpha}{g} \sqrt{v_{0}^{2} \sin ^{2} \alpha+2 g\left(\zeta_{D}+\bar{H}_{\zeta}\right)}, 0\right) .
$$

If this projectile landed in the interval $(-1 \sigma,+1 \sigma)$, then accordingly to (7) and the value of the Laplace function [11], the number $\bar{H}_{\zeta}$ must belong to the interval

$$
\begin{aligned}
& \Delta_{1} \equiv \frac{1}{2 g}\left(\frac{0,68 \sigma g}{v_{0} \cos \alpha}\right)^{2}-\frac{0,68 \sigma g}{v_{0} \cos \alpha} \sqrt{v_{0}^{2} \sin ^{2} \alpha+2 g \zeta_{D}}<\bar{H}_{\zeta}< \\
& \frac{1}{2 g}\left(\frac{0,68 \sigma g}{v_{0} \cos \alpha}\right)^{2}+\frac{0,68 \sigma g}{v_{0} \cos \alpha} \sqrt{v_{0}^{2} \sin ^{2} \alpha+2 g \zeta_{D}} \equiv \Delta_{2} .
\end{aligned}
$$

Similarly, we find values $\bar{H}_{\zeta}$ for which the point A belongs to the intervals $(+1 \sigma,+2 \sigma),(+2 \sigma,+3 \sigma)$, $(+3 \sigma,+4 \sigma)$ :

$$
\begin{aligned}
& \frac{1}{2 g}\left(\frac{0,68 \sigma g}{v_{0} \cos \alpha}\right)^{2}+\frac{0,68 \sigma g}{v_{0} \cos \alpha} \sqrt{v_{0}^{2} \sin ^{2} \alpha+2 g \zeta_{D}}<\bar{H}_{\zeta} \\
& <\frac{1}{2 g}\left(\frac{1,35 \sigma g}{v_{0} \cos \alpha}\right)^{2}+\frac{1,35 \sigma g}{v_{0} \cos \alpha} \sqrt{v_{0}^{2} \sin ^{2} \alpha+2 g \zeta_{D}}, \\
& \Delta_{3} \equiv \frac{1}{2 g}\left(\frac{1,35 \sigma g}{v_{0} \cos \alpha}\right)^{2}+\frac{1,35 \sigma g}{v_{0} \cos \alpha} \sqrt{v_{0}^{2} \sin ^{2} \alpha+2 \zeta_{D} g}<\bar{H}_{\zeta} \\
& <\frac{1}{2 g}\left(\frac{2,06 \sigma g}{v_{0} \cos \alpha}\right)^{2}+\frac{2,06 \sigma g}{v_{0} \cos \alpha} \sqrt{v_{0}^{2} \sin ^{2} \alpha+2 \zeta_{D} g} \equiv \Delta_{4}, \\
& \frac{1}{2 g}\left(\frac{2,06 \sigma g}{v_{0} \cos \alpha}\right)^{2}+\frac{2,06 \sigma g}{v_{0} \cos \alpha} \sqrt{v_{0}^{2} \sin ^{2} \alpha+2 \zeta_{D} g}<\bar{H}_{\zeta} \\
& <\frac{1}{2 g}\left(\frac{5 \sigma g}{v_{0} \cos \alpha}\right)^{2}+\frac{5 \sigma g}{v_{0} \cos \alpha} \sqrt{v_{0}^{2} \sin ^{2} \alpha+2 \zeta_{D} g} \equiv \Delta_{5} .
\end{aligned}
$$

The maximum values of the muzzle cut D center's displacement, which in the reference frame $C \xi \eta \zeta$ has 
coordinates, $D(0.3,0,1.2)$ are given in the Table 2 . The results in it are obtained while the combat-wheeled vehicles move with the speed $10 \mathrm{~m} / \mathrm{s}$ along the path with single irregularities of $0.3 \mathrm{~m}$ in length and $0.2 \mathrm{~m}$ in height.
The values of the change of the numbers $\bar{H}_{\zeta}$ for the tank machine gun are given in the Table 3. To obtain these values we use the shooting table [12] for the $7,62 \mathrm{~mm}$ projectiles of the tank machine gun.

Table 2

Maximum values of displacements of the point of departure of the projectile for different values of the parameter $v$

\begin{tabular}{|c|c|c|c|}
\hline & $v=0$ & $v=2 / 7$ & $v=-2 / 7$ \\
\hline$a$, rad. & 0,1483 & 0,1673 & 0,1269 \\
\hline$H_{\xi}, m$ & 0.1847 & 0.2091 & 0.1573 \\
\hline$H_{\zeta}, m$ & 0.0820 & 0.0859 & 0.0771 \\
\hline
\end{tabular}

Table 3

The values of the deviation $\bar{H}_{\zeta}$ from the center of dispersion of projectiles for the different angles of departure of the projectile $(\alpha)$ and the median deviations in range $(\sigma)$

\begin{tabular}{|c|c|c|c|c|c|c|c|c|}
\hline$\alpha$ & $\sigma$ & $\zeta_{D}$ & $\mathrm{~V}_{0}$ & $\Delta_{1}$ & $\Delta_{2}$ & $\Delta_{3}$ & $\Delta_{4}$ & $\Delta_{5}$ \\
\hline 8,5 & 40 & 2,8 & 855 & $-4,06497$ & 4,071792 & 8,093622 & 12,3663 & 30,17647 \\
\hline 9,6 & 40 & 2,8 & 855 & $-4,59935$ & 4,606591 & 9,155416 & 13,98662 & 34,11027 \\
\hline 12,5 & 40 & 2,8 & 855 & $-6,02642$ & 6,034734 & 11,9909 & 18,31368 & 44,61607 \\
\hline 30 & 40 & 2,8 & 855 & $-15,6917$ & 15,70218 & 31,18637 & 47,609 & 115,766 \\
\hline 6,5 & 35 & 2,8 & 855 & $-2,7144$ & 2,718387 & 5,40432 & 8,258757 & 20,1678 \\
\hline 10 & 35 & 2,8 & 855 & $-4,19577$ & 4,201128 & 8,348133 & 12,75102 & 31,07352 \\
\hline 18 & 35 & 2,8 & 855 & $-7,72804$ & 7,734727 & 15,36392 & 23,45748 & 57,06905 \\
\hline 21 & 35 & 2,8 & 855 & $-9,12976$ & 9,136679 & 18,14752 & 27,70554 & 67,38493 \\
\hline 6,5 & 30 & 2,8 & 855 & $-2,3271$ & 2,329575 & 4,630418 & 7,074613 & 17,26122 \\
\hline 7,4 & 30 & 2,8 & 855 & $-2,65132$ & 2,654191 & 5,274899 & 8,058077 & 19,64861 \\
\hline 13 & 30 & 2,8 & 855 & $-4,70791$ & 4,712052 & 9,360557 & 14,29281 & 34,78469 \\
\hline 16,5 & 30 & 2,8 & 855 & $-6,03954$ & 6,044059 & 12,00517 & 18,3286 & 44,58333 \\
\hline
\end{tabular}

\section{General conclusions}

The system of sprinkling with a progressive or regressive characteristic of elastic shock absorbers gives the high-quality new properties to the sprinkled part's oscillations of the combat-wheeled vehicles namely the period or the eigen frequency of the sprinkled part's oscillations of the combat-wheeled vehicles depends on the amplitudes.

We conclude that the magnitude of the amplitude of the transverse angular oscillations is smaller in the combat wheeled vehicle's motion along the path with the single small value irregularities for higher velocities of the combat wheeled vehicles and the milder characteristics of elastic shock absorbers (a lower value of the parameter $v$ ). At the speeds of $10 \mathrm{~m} / \mathrm{s}$, the amplitude of transverse angular oscillations of the output of a single irregularity for the progressive characteristics of the elastic shock absorbers can be up to $25 \%$ higher than for its linear analogue, at the same time for regressive to $22 \%$ less.
The magnitude of the dispersion, which is predetermined sprinkled part's oscillations of the combatwheeled vehicles increases, moreover for the combatwheeled vehicles with the regressive force characteristics of the elastic shock absorbers during the motion along the path with single irregularities the size of the dispersion region is less than for the progressive ones.

Therefore, we can state that the performance of the main functional assignments of the combat-wheeled vehicles' sprinkled part must be adaptive to the static deformation of the elastic shock absorbers $0.15<\Delta_{s t}<0.3 m$ and the nonlinearity parameter $-4 / 7<v<4 / 5$.

\section{Bibliography}

1. Bozhkova L. Influence of the cross-section forced fluctuations of a body on car over turning at an obstacle detour / L. Bozhkova, V. Ryabov, G. Noritsina // Transport business of Russia. - 2009. - № 3. - P. 141-151.

2. Grubel M.H. Oscillations of the sprung part of wheeled vehicles and its influence on road holding along the curvilinear stretch of a track / M.H. Grubel, M.B. Sokil, 
R.A. Nanivskyy // Scientific Bulletin of UNFU. - 2014. Vol. 24.1. - P. 155-162.

3. Nanivskyy R.A. Motion Stability of Wheeled Vehicles While Driving Along the Curved Parts of Track with the Roughnesses // Scientific Bulletin of UNFU. - 2014. Vol. 24.11. - P. 192-197.

4. Soltus A.P. The theory of operational properties of the vehicle: Textbook for universities // A.P. Soltus. - K.: Aristey, 2010. $-155 \mathrm{p}$.

5. Hrubel M. Influence of characteristics of wheeled vehicle suspensions of its road-holding along curved stretches of trac/ M. Hrubel, R. Nanivskyi, M. Sokil // Science \& military. - LiptovscyMikulas, Slovak Republska. - 2014. Vol. 99. - № 1. - P. 15-19.

6. Hrechanuk M. Improvement of air spring suspension of semitrailer truck / M. Hrechanuk // Bulletin of the Donetsk academy of automobile transport. - 2011. - V. 4. - P. 48-52.

7. Sokil B. Own vertical fluctuations of the car body with the nonlinear characteristics of the elastic suspension / B. Sokil, R. Nanivskyy, M. Grubel // Ukrainian Road Vehicle:
Research and Production Magazine. - 2013. - № 5 (235). P. 15-18.

8. Adaptive suspension: the device, the principle of action: http://www.autoobserver.ru/sistemi-auto/76-adaptivnayapodveskaustroystvo-i-princip-deystviya-aktivnoypodveski.html.

9. Wan der Pol. A teory of the amplitude of free andforced triode vibrations / Wan der Pol // Radio Review. - 1920. № 1. - P. 701-710.

10. Petrenko V. Artillery shooting / V. Petrenko, V. Zhytnyk, V. Makeev, Yu. Repilo, O. Meschkov. - Sumy: Sumy State University, 2012. - 757 p.

11. Seno P. Probability Theory and Mathematical Statistics: Textbook/P. Seno. - Kyiv: Knowledge, 2007. - 556 p.

12. Vakhinin O.V. Shortened shooting tables for the 152-mm self-propelled howitzers 2C3. / O.V. Vakhinin, O.V. Podlesniy. Lviv: National Academy of Army, 2016. - 115 p.

Рецензент: д.ф.-м.н., проф. М.Г. Стащук, Фізико-механічний інститут імені Г.В. Карпенка НАН України, Львів.

\title{
ВПЛИВ СИЛОВИХ ХАРАКТЕРИСТИК СИСТЕМИ ПІДЕСОРЮВАННЯ БОЙОВИХ КОЛІСНИХ МАШИН НА ЕФЕКТИВНІСТЬ ВЕДЕННЯ ВОГНЮ 3 ХОДУ
}

А.І. Андрухів, Н.М. Гузик, Р.А. Нанівський, М.Б. Сокіл

Розроблено методику дослідження впливу силових характеристик системи підресорювання бойових колісних машин на поперечні коливання підресореної частини, а відтак - ефективність ведення вогню з ходу із стаціонарно встановленої стрілецької зброї.

Показано, що величина розсіювання зумовлена вказаними коливаннями підресореної частини зростає, причому для випадку прогресивної силової характеристики пружних амортизаторів під час руху вздовж шляху із поодинокими нерівностяли величина області розсіювання є більшою, ніж для регресивної.

Ключові слова: система підресорювання, бойова колісна машина, амплітуда, частота коливань.

\section{ВЛИЯНИЕ СИЛОВЫХ ХАРАКТЕРИСТИК СИСТЕМЫ ПОДРЕССОРИВАНИЯ БОЕВЫХ КОЛЁСНЫХ МАШИН НА ЭФФЕКТИВНОСТЬ ВЕДЕНИЯ ОГНЯ С ХОДУ}

\author{
А.И. Андрухив, Н.Н. Гузык, Р.А. Нанивский, М.Б. Сокил
}

Разработана методика исследования влияния силовых характеристик системы подрессоривания боевых колесных машин на поперечные колебания подрессоренной части, то есть - эффективность ведения огня с ходу со стационарно установленного стрелкового оружия.

Показано, что величина рассеивания обусловлена указанныли колебаниями подрессоренной части возрастает, причем для случая прогрессивной силовой характеристики упругих амортизаторов при движении вдоль пути с единичныли неровностями величина области рассеяния является большей, чем для регрессивной.

Ключевые слова: система подрессоривания, боевая колесная машина, амплитуда, частота колебаний. 